\title{
Optimization and design of carbon fabricreinforced cementitious matrix composites
}

DOI:

10.1002/suco.202000801

\section{Document Version}

Accepted author manuscript

Link to publication record in Manchester Research Explorer

\section{Citation for published version (APA):}

Su, M., Wang, Z., \& Ueda, T. (2022). Optimization and design of carbon fabricreinforced cementitious matrix composites. Structural Concrete. https://doi.org/10.1002/suco.202000801

\section{Published in:}

Structural Concrete

\section{Citing this paper}

Please note that where the full-text provided on Manchester Research Explorer is the Author Accepted Manuscript or Proof version this may differ from the final Published version. If citing, it is advised that you check and use the publisher's definitive version.

\section{General rights}

Copyright and moral rights for the publications made accessible in the Research Explorer are retained by the authors and/or other copyright owners and it is a condition of accessing publications that users recognise and abide by the legal requirements associated with these rights.

\section{Takedown policy}

If you believe that this document breaches copyright please refer to the University of Manchester's Takedown Procedures [http://man.ac.uk/04Y6Bo] or contact uml.scholarlycommunications@manchester.ac.uk providing relevant details, so we can investigate your claim.

\section{OPEN ACCESS}


Su, M.N., Zhi, W., Ueda, T. (2022) "Optimization and Design of Carbon Fabric-Reinforced Cementitious Matrix Composites", Structural Concrete, FIB, pp. 1-16. DOI: $10.1002 /$ suco.202000801

1

Optimization and Design of Carbon Fabric-Reinforced Cementitious

\section{Matrix Composites}

$$
\text { Mei-ni } \mathrm{SU}^{1} \text {, Zhi WANG }{ }^{2} \text {, Tamon } \mathrm{UEDA}^{3 *}
$$

${ }^{1}$ Senior Lecturer, Department of Mechanical, Aerospace and Civil engineering. University of Manchester, Manchester, Sackville Street, Manchester, M1 7JR, UK. Email: meini.su@manchester.ac.uk

${ }^{2}$ MSc student, Guangdong Province Key Laboratory of Durability for Marine Civil Engineering, College of Civil and Transportation Engineering, Shenzhen University, Shenzhen, Guangdong 518060, China. Email: wangzhi2017@email.szu.edu.cn

$3^{*}$ Distinguished Professor, Guangdong Province Key Laboratory of Durability for Marine Civil Engineering, College of Civil and Transportation Engineering, Shenzhen University, Shenzhen, Guangdong 518060, China. Email: ueda@szu.edu.cn (Corresponding author)

Abstract: Interest in carbon fabric-reinforced cementitious matrix (C-FRCM) composites as structural strengthening materials for reinforced concrete structures has recently increased. In such applications, the mechanical properties of C-FRCM composites are the key to unlocking the corresponding strengthening effects. Therefore, this study explores different optimization approaches to improve the loading behaviors of C-FRCM composites, such as different carbon fabric contents in the cementitious matrix and different surface treatments of the carbon fiber meshes. Then, a series of tensile tests are carried out to evaluate the performance of the modified C-FRCM composites. Furthermore, experimental results of other FRCM composites are collected from the literature to create a larger data pool for analysis. Finally, two existing constitutive models for FRCM composites — the Aveston-Cooper-Kelly (ACK) model and the AC434 model — are compared against these experimental data.

Key words: C-FRCM; carbon fiber mesh; constitutive models; tensile tests 


\section{Introduction}

Externally bonded fiber composite materials have become a common a common means to improve the performance and extend the service life of existing reinforced concrete structures.

Over the last 20 years, fiber-reinforced polymer (FRP) plates/sheets/meshes, consisting of continuous fiber sheets and organic epoxy resin, have been the most popular strengthening materials [1,2]. However, externally bonded FRP systems are difficult to construct in low-temperature environments and are not durable in humid and corrosive environments; furthermore, FRP systems have poor fire resistance properties and are incompatible with concrete substrates (due to the different chemical properties between organic and inorganic materials) [3-8]. With the development of structural strengthening technologies, a relatively new composite called fabric-reinforced cementitious matrix (FRCM) composite has attracted attention from researchers and engineers. FRCM composites are a type of composite with one or multiple layers of continuous bidirectional fiber mesh embedded in a cementitious matrix [9-12]. Compared to the bonding material used in FRPs (e.g., epoxy resin), the inorganic cementitious materials used in FRCM composites are superior in terms of fire resistance, durability and compatibility with concrete (i.e., allows vapor permeability and application on a wet surface). FRCM composites also exhibit advantages over FRPs in applications on irregular surfaces [13].

Although both FRPs and FRCM composites are mainly subjected to tension when used for structural strengthening, the structural responses of these two composites are quite different. The stress-strain curve of an FRP under tension is linear until reaching the ultimate state, whereas the load transfer in an FRCM composite occurs through the interfacial bond 
between the cement matrix and the fiber mesh, and the corresponding constitutive model for an FRCM composite is bilinear or trilinear, for which the cracking of the cementitious matrix corresponds to a transition point [14]. Research on FRPs started in the 1940s, and FRPs began to be implemented in a wide range of applications in the 1960s. Compared to FRPs, FRCM composites have more-complex structural responses; research on FRCM composites started in the 1980s. The tensile properties of FRCM composites were significantly connected to the bond behavior between matrix and fiber, while the strengthening intervention also relies on the composite/substrate bond behavior. According to the literatures, the fiber mesh/cementitious matrix interface is normally more critical compared to the composite/substrate interface $[11-12,15-18]$. This is because cementitious matrix and concrete are both inorganic materials; the bonding between inorganic materials is typically better than the bonding between inorganic and organic materials. Existing experimental investigations on the tensile behavior of FRCM composites include the clarification of the effects of clamping grips (i.e., different boundary conditions) [19,20], layers of fiber mesh $[8,21,22]$, and chopped fibers in the cementitious matrix [23] on the loading behaviors of the composites. Experimental results have shown that the mechanical properties of FRCM composites could be significantly limited due to the combination of premature filament failure and core filament slippage [11-12, 24-25]. Compared to clevis grips, clamping grips resulted in a better utilization of the capacities of fibre meshes which embed in cementitious matrix, thereby leading to generally higher tensile strength results $[19,20]$. In the macro level, Larrinaga et al. [21], Caggegi et al. [22] and Donnini and Corinaldesi [8] found that as the number of fiber layers increased, the bond between the fiber bundles and mortar became less 
effective, and the fiber bundles became more prone to slip. Barhum and Mechtcherine [23] incorporated chopped glass and carbon fibers into a cementitious matrix and reported that the cracking load of the composite materials significantly increased and that a greater number of fine cracks appeared on the specimen surface due to the incorporation of the reinforcing materials; however, the increase in ultimate strength was limited. Studies on the surface treatment of fiber bundles have also been carried out. Contamine and Si Larbi [26] preimpregnated glass fiber meshes with epoxy resin and latex before embedding the fiber meshes into a cementitious matrix; this process significantly increased the strength of the FRCM composites. This increase in strength occurred because the preimpregnation process resulted in the fiber filaments having a more uniform stress distribution [27]. Donnini et al. [15] used different mortar matrices and applied different coating treatments to carbon fabric. The results show that the use of a polymer coating on carbon fabric increases the mechanical capacity of the FRCM system. In addition, applying sand to the surface of carbon fabric further increased the mechanical characteristics of the carbon fabric. Other studies have investigated different anchorage configurations of embedded fiber meshes [28], effective fiber mesh overlap lengths [29] and loop-shaped elements [30] to improve the loading behaviors of FRCM composites. However, the experimental results presented in the literature are still limited. Moreover, as mentioned above, the loading responses of FRCM composites are quite distinct under different conditions, making it difficult to reach consistent conclusions for different FRCM composites, considering that there are a substantial number of variables associated with the cementitious matrix, embedded fiber meshes, loading configurations, etc. Currently, there are two commonly used simplified tensile stress-strain models for FRCM 
composites: the bilinear model codified in AC434.13 [31] (called the AC434 model in the following discussion) and the trilinear model proposed by Aveston and Kelly [32] (called the ACK model in the following discussion). The appropriateness of these two existing models for different FRCM composites requires investigation.

Thus, this study aims to further optimize FRCM composites with reference to the commercial products and engineering cementitious composites (ECCs) available and to evaluate the appropriateness of the existing FRCM constitutive models against the newly developed and collected experimental results. First, different modifications regarding the cementitious matrix and carbon fiber mesh (CF-MESH) are used to prepare new carbon FRCM (C-FRCM) composites. Although it is the flexural behavior of the FRCM composite which is closely related to the design, tension properties of the FRCM could be used to initially assess the quality of the FRCM composites. Uniaxial tensile tests are carried out to obtain the stress-strain curves of these C-FRCM composites. The types of considered cementitious materials include mortar, mortar with chopped carbon fibers, ECC and commercial mortar; the types of CF-MESH considered in this study include dry CF-MESH without a coating, CF-MESH coated at the nodes and commercial carbon FRP (CFRP) grids. In addition, this paper summarizes the existing results of tensile tests on FRCM composites available in the literature to form a larger data pool with the newly generated test results. Based on this data pool, the AC434 model and ACK model are assessed, and suggestions for FRCM composite design are discussed. To simulate the real load transfer mechanism in structures, beam bending tests are needed in the future, but that should be built on the development of a reasonably good FRCM composite, which is the main purpose of this study. 


\section{Experimental program}

\subsection{Raw materials}

The embedded carbon fibers used in this study are the dry CF-MESH shown in Figure 1(a) (denoted as T1 - TEX of 1200g/km, non-woven), and the coated carbon fiber mesh shown in Figure1(b) (denoted as T2 - weight of the mesh of $200 \mathrm{~g} / \mathrm{m}^{2}$, woven). The reason for including the commercial products with polymer-impregnated textiles is to see the possible improvement of bond brought by the coating. CF-MESH T3 represents CF-MESH T1 with coating at selected nodes (see Figure 1(c)), which were along the whole length of the textile strip embedded in the tensile coupon. The material used resulted in coating of the yarns' junctions. Uniaxial tensile tests of a single bundle of fibers from the aforementioned three meshes (three parallel tests for each type of mesh) were carried out using a $10 \mathrm{kN}$ servo-controlled testing machine, and the average test results are presented in Table 1. Note that during the tensile test of $\mathrm{T} 2$ fiber, the premature slippage between the fibers and its coating was occurred, which caused the fiber to slip out of the clamping jaws. Whereas, for the other specimens, the failure mode is fiber breakage. This is the main reason causing the large difference of the tensile strength between T2 and the others. Seven different types of cementitious materials were considered in this study; more information about these materials is provided in Table 2. According to the manufacturer, the commercial mortar (M7) contains an activator which can actively react with the coating of CF-MESH, and thus improve the bonding between CF-MESH (T2) and mortar (M7). The compressive, and flexural properties of cementitious materials after 28 days of curing (temperature $20^{\circ} \mathrm{C}$, relative humidity $100 \%$, complied with Chinese standard GB/T50081-2016 [33] were obtained by tests conducted in 
accordance with EN 1015-11 [34]. The tensile properties after 28 days of curing were obtained by dog bone tensile test in accordance with JSCE [35], as shown in Table 2, which were thereafter used in the calculation in Section 6. The dimensions of the specimens used for the compression tests are $40 \mathrm{~mm} \times 40 \mathrm{~mm} \times 40 \mathrm{~mm}$, whereas the dimensions for the three-point bending test specimens are $40 \mathrm{~mm} \times 40 \mathrm{~mm} \times 160 \mathrm{~mm}$. Three parallel tests were conducted for each type of cementitious matrix. The length of chopped carbon fibers is $6 \mathrm{~mm}$.

\subsection{Test specimens}

A total of eight different FRCM composites were considered in this study, and three tests were conducted for each composite. The labeling scheme for the specimens is given in Table 3. The preparation procedure of the FRCM composites includes the following steps: (1) place a $5 \mathrm{~mm}$ cementitious matrix in a wooden mold (Figure 2(a)), (2) firmly fix a layer of mesh on top of the cementitious matrix (see Figure 2(b)), (3) place another $5 \mathrm{~mm}$ cementitious matrix layer on top of the mesh and trowel its surface, and (4) demold the FRCM composite coupon after 24 hours (Figure 2(c)). The FRCM composite coupons were then cured for 28 days at $20{ }^{\circ} \mathrm{C}$ and $70 \%$ humidity. Afterwards, each FRCM composite plate was cut into three specimens using a diamond cutter for tests (Figure 2(d)); each specimen contained five fiber bundles in the longitudinal direction. Figure 3 shows the dimensions of a FRCM composite tensile specimen., the length of the FRCM-anchorage plate is $100 \mathrm{~mm}$.

\subsection{Test setup and measurements}

Uniaxial tensile tests were performed in accordance with ACI 549.4R-13 [36] and AC 434.13 
specimen deformation was measured with two symmetrically arranged linear variable differential transformers (LVDTs) (Figure 4(a)). The loads and specimen deformations were synchronously collected with a datalogger. Both ends of the specimen were hinged to the machine to avoid bending moments, as shown in Figure 4(b).

\section{Experimental results}

The stress-strain curves obtained from the tensile tests are shown in Figure 5, and the test results, including the cracking strength $\left(f_{t}\right)$, peak strength $\left(f_{u}\right)$, ultimate strain $\left(\varepsilon_{u}\right)$, uncracked modulus $\left(E_{1}\right)$ and post-cracking modulus $\left(E_{2}\right)$, are presented in Table 4 . Note that the post-cracking modulus is the linear fitting result of the post-cracking stress-strain curve. In the initial stage of loading, the load was mainly carried by the cementitious matrix and the CF-MESH. The first part of the stress-strain curve is linear. Later, cracks occurred on the surface of the cementitious matrix when the ultimate strain was reached. The load suddenly dropped when new cracks occurred; thus, the stress-strain curves fluctuate during this stage. Afterwards, when the number of cracks became stable, the load started to increase gradually again until reaching the peak value; during this stage, the load was transferred from the cementitious matrix to the CF-MESH and was carried by the CF-MESH. Both this study and previous investigations $[2,15,24,37]$ found that the typical failure mode of FRCM composites is a combination of slippage between the CF-MESH and the cementitious matrix and partial

177 fracturing of external carbon fiber filaments in the CF-MESH.

\subsection{Effect of chopped carbon fibers}

179 The effect of the number of chopped carbon fibers (see Figure 6) in the cementitious matrix is considered by comparing the performance of specimens M2-T1, M3-T1, M4-T1, and M5-T1 
with the reference specimens M1-T1 (specimens without chopped carbon fibers); the results are shown in Figure 5(a) and Table 4. The test program included four different chopped fiber loadings: $0.50 \%, 0.75 \%, 1.00 \%$ and $1.25 \%$ of the cement weight. The cracking strength of the specimens with chopped fibers was $28-45 \%$ higher than that of the corresponding reference specimens; this result is consistent with the findings reported in previous studies [23], which stated that chopped fibers can effectively inhibit the cracking of cementitious materials. When the chopped fiber content was less than $0.75 \%$ of the cement weight, the mechanical properties of the FRCM composite, such as the cracking strength, ultimate strength and modulus, increased. However, when the chopped fiber content exceeded $0.75 \%$ of the cement weight, the excess chopped fibers decreased the FRCM composite strength. It is presumed that the main reason for this phenomenon is that the excess fibers could not be sufficiently dispersed, causing the agglomeration of fibers in the cementitious material.

\subsection{Effect of node coating in a CF-MESH}

Based on the literature review, coating a CF-MESH could improve the uniformity of the stress distribution in the fiber bundles because the coating can penetrate the core of the yarns, thereby increasing the inner bond between the fiber filaments [27,38]. Therefore, specimens M1-T3 were prepared to investigate the node coating. A comparison of the stress-strain curves of specimens M1-T3 and that of the reference specimens (M1-T1) is shown in Figure 5(b). Before the reference specimens failed, the stress-strain curves of M1-T3 consistently coincided with those of the reference specimens. Afterwards, the M1-T3 curves continued to increase stably. The ultimate strength, ultimate strain and post-cracking modulus of specimens 
In the failed M1-T3 specimens, partial fracturing of the fiber bundles was observed (see Figure 7). Similar experimental results were also reported by Kim et al. [28].

\subsection{Performance of ECC as a cementitious material}

ECC is also a type of cement-based composite that has recently attracted extensive research interest $[39,40]$ due to its advantageous characteristics such as a high toughness, impact resistance, freeze-thaw resistance and fatigue resistance. The key difference between ECCs and other cementitious materials is the high ductility characteristics of ECCs. In this study, ECC is also used as an alternative bonding material for CF-MESH (i.e., specimen M6-T1); the experimental results are presented in Table 4, and the stress-strain curves are shown in Figure 5(c). The M6-T1 specimens clearly exhibited multiple cracking characteristics, wherein new fine cracks continued to appear throughout the entire loading process until specimen failure (see Figure 8). The number of cracks in the M6-T1 specimens was seven times that in the reference specimens, whereas the crack width in the former specimens was notably smaller. For the reference specimens, before the width of the crack suddenly increased, the load was resisted mainly by the bond capacity of the CF-MESH/cementitious matrix. When a major crack occurred, the carbon fiber bundles and cementitious matrix started to experience slippage, and the load was resisted mainly by friction at the CF-MESH/cementitious matrix interface and the external part of the carbon fiber filaments. It should be noted that before matrix-fiber friction is engaged, the matrix-fiber bond capacity should be exploited [41]. However, for the M6-T1 specimens, no major cracks occurred in the cementitious material, and the load was resisted by both the CF-MESH and the ECC 
specimens were close to those of the reference specimens, the ultimate strength, ultimate strain and post-cracking modulus results of the M6-T1 specimens were $77 \%, 18 \%$ and $83 \%$ higher than those of the reference specimens, respectively.

\subsection{Performance of commercial FRCM composite}

For comparison, a commercial FRCM composite (specimens M7-T2) was also considered herein to understand the quality parameters of products on the market and explore whether our FRCM composite materials can generally meet the market requirements. The stress-strain curves from the tests of this material are shown in Figure 5(d), and the test results are presented in Table 4. During loading, all the fiber bundles were pulled out from the cementitious matrix, and the coating on the surface of the fiber bundles peeled off, as shown in Figure 9. This failure mode suggests that the poor performance of the commercial FRCM composites was caused by the premature slippage of the fibers and their coating, although the coating had reasonably good bonding with the cementitious matrix. Thus, the mechanical properties of the commercial FRCM composite specimens were not as good as those of the reference specimens: the cracking strength, ultimate strength, ultimate strain and postcracking modulus of M7-T2 were $69 \%, 84 \%, 36 \%$, and $59 \%$ lower than those of the reference specimens, respectively.

\section{Experimental data collected from the literature}

243 A number of tensile tests on FRCM composites have been carried out and reported in the literature. This paper summarizes a total of 29 available test results covering different fiber meshes (i.e., carbon, glass, polyparaphenylene benzobisoxazole (PBO) and basalt fibers), 
data were used with the 24 newly generated test results from this study to form a large data pool for the following discussions. Note that data of only FRCM composites with a single layer of fiber mesh were collected herein and that the stress of the FRCM composites during the tensile test was calculated by dividing the load by the cross-sectional area of the fiber. In these calculations, note that $f_{f}$ represents the ultimate tensile strength of the fiber, whereas $\varepsilon_{f}$ represents the ultimate tensile strain of the fiber.

\section{Discussion on the testing configuration}

The experimental data show that in addition to the parameters of the FRCM composites discussed in Section 3, the gripping devices used also affect the structural responses of FRCM composites. The two commonly used gripping devices are clamping grips and clevis grips. The clamping grip method [36] is to directly clamp the ends of the FRCM specimens using the wedge-shaped chuck of the testing machine (the load can be applied to the specimens), and the clevis grip method [19] is to using metallic plates bonded to the specimen ends and connected to the machine (the load is transferred to the specimens through the metallic plates). The tensile behavior of FRCM composites is related to the test set-up adopted. If clevis grip tensile tests are carried out, a bi-linear behavior is generally observed, whereas clamping grip test set-ups usually provide tri-linear curves [42]. The ultimate strength results of the tested FRCM composites with respect to the ultimate strengths of the fibers is shown in Figure 10. In general, when using clamping grips, the ultimate strength results of the FRCM composites

267 effectively improves the interfacial friction between the cementitious matrix and the 
which enables the mechanical properties of the CF-MESH to be better utilized. In contrast, when using clevis grips, the ultimate strength results of the FRCM composites are notably

271 lower than those of the fiber bundles without extra pressure from the grips. Notably, FRCM composites are generally not subjected to lateral pressure when externally bonded to concrete structures as strengthening materials in practical engineering applications. Therefore, FRCM composites are generally not subjected to lateral pressure when externally bonded to concrete structures as strengthening materials in practical engineering applications and the clevis grip configuration can more closely resemble the in situ cases which has limited length to fix both ends of the FRCM composite.

\section{Discussion on the constitutive models}

\subsection{AC434 model and result comparison}

The bilinear simplified model for FRCM composites is codified in AC434 [31] with the symbols defined in Figure 11. The model provided by AC434 [31] describes the idealized behavior of a clevis-type test providing a methodology to identify the parameters that will be used in the design of the strengthening intervention, according to ACI 549.4R-13 [36]. In the AC434 model, the stress-strain curve is simplified into two linear parts. The first part of the curve corresponds to the first loading stage (i.e., the uncracked stage). The slope of the linear part corresponding to the uncracked behavior of the specimen can be defined by two points within this linear range [31]. Thus, the tensile elastic modulus $E_{1-A C 434}$ of the uncracked specimen is calculated using the following expression:

$$
E_{1-A C 434}=\frac{\Delta f}{\Delta \varepsilon}
$$


difference in tensile strain between two selected points.

After the specimen cracks, some experimental results [27] suggest that new cracks are

generated as the crack expansion and fiber filament slippage occurs. According to AC434, two points are selected on the experimental curve at a stress level equal to $0.90 f_{u}$ and $0.60 f_{u}$. The slope of the line that connects these two points represents the tensile modulus at the post-cracking modulus. Note that the tensile specimen must have sufficient fabric area to achieve $50 \%$ strength over transition point, so that the selected two points will be in the correct part of the curve. The modulus $E_{2-A C 434}$ (Eq. 2) is used to define the second linear part of the curve.

$$
E_{2-A C 434}=\frac{0.9 f_{u}-0.6 f_{u}}{\varepsilon_{u @ 0.9 f_{u}}-\varepsilon_{u @ 0.6 f_{u}}}
$$

Where $f_{u}$ is the experimental ultimate strength.

The intersection point of the initial and secondary parts of the curves corresponds to the cracking strength $f_{t-A C 434}$ and the cracking strain. Thus, the cracking strength can be calculated by the mathematical relationship according to Figure 11, as shown in Eq. 3:

$$
f_{t-A C 434}=E_{1-A C 434} \varepsilon_{t-A C 434}=E_{2-A C 434} \varepsilon_{t-A C 434}+\left(f_{u}-E_{2-A C 434} \varepsilon_{u}\right)
$$

By converting Eq. 3, the cracking strain $\mathcal{E}_{t-A C 434}$ can be obtained as follows:

$$
\varepsilon_{t-A C 434}=\frac{f_{u}-E_{2-A C 434} \varepsilon_{u}}{E_{1-A C 434}-E_{2-A C 434}}
$$

The cracking strength $f_{t-A C 434}$ can be calculated with the following expression:

$$
f_{t-A C 434}=E_{1-A C 434}\left(\frac{f_{u}-E_{2-A C 434} \varepsilon_{u}}{E_{1-A C 434}-E_{2-A C 434}}\right)
$$

The stress-strain curves obtained from the experiments are compared to the results from 
closely with most of the experimental curves except those of M7-T2. The uncommon stress-strain curves of the M7-T2 specimens might be due to the premature debonding between the fiber bundles and their coating. AC434 models are also compared to the new and collected test results, as shown in Figure 13. For cracking strength (see Figure 13(a)), the AC434 model generally underestimated the test results. In terms of the postcracking modulus (see Figure 13(b)), the predictions of the AC434 model were more accurate and consistent with the experimental results.

\subsection{ACK model and result comparison}

The ACK model for FRCM composites (see Figure 14) was proposed by Aveston and Kelly [32] and Bertolesi et al. [7]. The ACK model can predict the tensile behavior of the FRCM composite once the properties of its components are known. In this model, the stress-strain curve has three stages: the uncracked stage, the crack development stage, and the crack expansion stage. The uncracked stage is the first elastic stage of the curve, which is defined by the initial elastic modulus $E_{l-A C K}$, as given by Eq. 6:

$$
E_{1-A C K}=E_{f} V_{f}+E_{m} V_{m}
$$
respectively.

where $E_{f}$ and $E_{m}$ are the tensile Young's modulus of the fiber and cementitious matrix, respectively, and $V_{f}$ and $V_{m}$ are the volume fractions of the fiber and the cementitious matrix, Figure 14), and the cracking strength $\left(f_{t-A C K}\right)$ can be calculated by Eq. 7:

$$
f_{t-A C K}=\frac{E_{1-A C K} f_{m}}{E_{m}}
$$


where $f_{m}$ is the tensile ultimate strength of the cementitious matrix.

Multiple fine cracks appear on the specimen as the load continues to increase $[44,45]$.

Slips at cementitious matrix and CF-MESH interface begin to take place after the first crack occurs. It is assumed that the frictional shear stress between the cementitious matrix and the

CF-MESH $(\tau)$ is constant. The spacing of the cracks $(\delta)$ is expressed with Eq. 8 based on the force equilibrium along the loading axis of the fiber [21]:

$$
\delta=\frac{r f_{m} V_{m}}{2 \tau V_{f}}
$$

[46] and Cuypers and Wastiels [44], the average distance between cracks is $1.337 \delta$, so the

[19]. The modulus $E_{2-A C K}$ in this stage can be obtained from Eq. 11.

$$
E_{2-A C K}=E_{f} V_{f}
$$


relevant for the high-performance matrices considered in this study. However, since the purpose of this study is to compare the predictions by the ACK model with the tensile behavior of the FRCM composites obtained from tests, the existing equations in the ACK model are remained.

The stress-strain curves obtained from the experiments are compared to the results from the ACK model in Figure 15. The ACK model can accurately predict the stress-strain curves in the uncracked stage for all the tested specimens. In the crack development stage, the ACK model curve is also close to the experimental curves of most specimens, with the exception of those of M6-T1 and M7-T2. However, the ACK model predictions for the crack expansion stage are significantly different from all the test curves. According to the discussion in Section 5, a possible reason for these discrepancies might be the use of clevis grips in this study; hence, the strength of the FRCM composite specimens did not continue to increase significantly after cracking without the presence of additional clamping pressure.

Furthermore, the predictions of the cracking strength and post-cracking modulus by the ACK models are also compared to the new and collected test results, as shown in Figure 16. For cracking strength (see Figure 16(a)), the ACK model significantly overestimated most of the test results. In terms of the post-cracking modulus (see Figure 16(b)), the predictions of the ACK model cannot accurately predict experimental values.

\section{Conclusions}

In this study, a total of eight different types of FRCM composites were considered by optimizing the cementitious matrix and carbon fiber meshes. Uniaxial tensile tests were carried out to obtain their structural responses and mechanical properties. The experimental 
results showed that including a small content of chopped carbon fibers (up to $0.75 \%$ of the cement weight) in the cementitious matrix and a preimpregnated epoxy coating on the nodes of the fiber meshes were beneficial for the mechanical properties of FRCM composites. In addition, ECC was also found to be a good bonding material for use in FRCM composites. delay the slippage of carbon fibers. Existing tensile test data of FRCM composites, covering different types of fiber meshes, cementitious materials and experimental gripping devices, were also collected from the literature. Both the newly generated experimental and the collected data are compared with AC434 model and ACK model. The AC434 model was found to be able to capture the experimental curves rather accurately; however, the predictions by the ACK model seems inaccurate. The prediction result of the ACK model overestimates most experimental data.

\section{Data Availability Statement}

Some or all data, models, or code that support the findings of this study are available from the corresponding author upon reasonable request.

\section{References}

393

[1] Chen PY, Pei C, Zhu JH, Su MN, Xing F. Sustainable recycling of intact carbon fibres from end-of-service-life composites. Green Chem 2019;21:4757-4768.

[2] Zhu JH, Chen PY, Su MN, Pei C, Xing F. Recycling of Carbon Fibre Reinforced Plastics by Electrically Driven Heterogeneous Catalytic Degradation of Epoxy Resin. Green Chem 2019;21:1635-47.

[3] D'Ambrisi A, Feo L, Focacci F. Bond-slip relations for PBO-FRCM materials externally bonded to concrete. Compos Part B - Eng 2012;43(8):2938-49.

[4] Nardone F, Ludovico MD, Basalo FJDCY, Prota A, Nanni A. Tensile behavior of epoxy based FRP composites under extreme service conditions. Compos Part B 2012;43(3):1468-74.

[5] D'Ambrisi A, Feo L, Focacci F. Experimental and analytical investigation on bond between Carbon-FRCM materials and masonry. Compos Part B - Eng 2013;46:15-20.

[6] D'Ambrisi A, Feo L, Focacci F. Experimental analysis on bond between PBO-FRCM strengthening materials and concrete. Compos Part B - Eng 2013;44(1):524-32.

[7] Bertolesi E, Carozzi FG, Milani G, Poggi C. Numerical modeling of Fabric Reinforce Cementitious Matrix composites (FRCM) in tension. Constr Build Mater 2014;70:531-48. 
[8] Donnini J, Corinaldesi V. Mechanical characterization of different FRCM systems for structural reinforcement. Constr Build Mater 2017;145:565-75.

[9] RILEM. Report 36: Textile Reinforced Concrete - State-of-the-Art, Report of RILEM TC 201-TRC, edited by Wolfgang Brameshuber, RILEM publications, 2006.

[10] Schladitz, F., Frenzel, M., Ehlig, D., Curbach, M., "Bending load capacity of reinforced concrete slabs strengthened with textile reinforced concrete", Engineering Structures, 2012; 40: 317-326.

[11] Shams, Ali ; Horstmann, Michael ; Hegger, Josef, "Experimental investigations on Textile-Reinforced Concrete (TRC) sandwich sections", Composite structures, 2014; 118: 643-653.

[12] Li, Y., Bielak, J., Hegger, J., Chudoba, R., "An incremental inverse analysis procedure for identification of bond-slip laws in composites applied to textile reinforced concrete", Composites. Part B, Engineering, 2018; 137:111-122.

[13] Papanicolaou CG, Triantafillou TC, Papathanasiou M, Karlos K. Textile reinforced mortar (TRM) versus FRP as strengthening material of URM walls: out-of-plane cyclic loading. Mater Struct 2007;41(1):143-157.

[14] Zhu JH, Wang Z, Su MN, Ueda T, Xing F. Confinement of C-FRCM Jacket for RC Columns under Impressed Current Cathodic Protection. J Compos Constr 2020;24(2):04020001.

[15] Donnini J, CorinaldesiV, Nanni A. Mechanical properties of FRCM using carbon fabrics with different coating treatments. Compos Part B - Eng 2016;88:220-28.

[16] Su M, Wei L, Zhu JH, Ueda T, Guo G, Xing F. Combined impressed current cathodic protection and FRCM strengthening for corrosion-prone concrete structures. $\mathrm{J}$ Compos Constr 2019;23(4):04019021.

[17] Wagner, J., Curbach, M., "Bond fatigue of TRC with epoxy impregnated carbon textiles", Applied sciences, 2019; 9 (10):1980.

[18] Herbrand, M., Adam, V., Classen, M., Kueres, D., Hegger, J., "Strengthening of existing bridge structures for shear and bending with carbon textile-reinforced mortar”, Materials, 2017; 10 (9): 1099.

[19] Arboleda D, Carozzi FG, Nanni A, Poggi C. Testing procedures for the uniaxial tensile characterization of fabric-reinforced cementitious matrix composites. J Compos Constr 2015;20(3):04015063.

[20] D'Antino T, Papanicolaou C. Comparison between different tensile test set-ups for the mechanical characterization of inorganic-matrix composites. Constr Build Mater 2018;171:140-51.

[21] Larrinaga P, Chastre C, San-José JT, Garmendia L. Non-linear analytical model of composites based on basalt textile reinforced mortar under uniaxial tension. Compos Part B - Eng 2013;55(55):518-27.

[22] Caggegi C, Lanoye E, Djama K, Bassil A, Gabor A. Tensile behaviour of a basalt TRM strengthening system: Influence of mortar and reinforcing textile ratios. Compos Part B - Eng 2017;130:90-102.

[23] Barhum R, Mechtcherine V. Effect of short, dispersed glass and carbon fibres on the behaviour of textile-reinforced concrete under tensile loading. Eng Fract Mech 2012;92:56-71.

[24] Häußler-Combe U, Hartig J. Bond and failure mechanisms of textile reinforced concrete (TRC) under uniaxial tensile loading. Cement Concrete Comp 2007;29(4):279-89.

[25] Adam, V., Bielak, J., Dommes, C., Will, N., Hegger, J., "Flexural and shear tests on reinforced concrete bridge deck slab segments with a textile-reinforced concrete strengthening layer", Materials, 2020; 13 (18): 4210.

[26] Contamine R, Si Larbi A. Development of a textile reinforced concrete (TRC) to retrofit 
reinforced concrete structures. Eur J of Environ Civ En 2016;20(6):626-42.

[27] D'Antino T, Papanicolaou C. Mechanical characterization of textile reinforced inorganic-matrix composites. Compos Part B - Eng 2017;78-91.

[28] Kim H-S, Truong GT, Park S-H, Choi K-K. Tensile Properties of Carbon Fibre-Textile Reinforced Mortar (TRM) Characterized by Different Anchorage Methods. Int J Concr Struct M 2018;12(1):73.

[29] Donnini J, Chiappini G, Lancioni G, Corinaldesi V. Tensile behaviour of glass FRCM systems with fabrics' overlap: Experimental results and numerical modeling. Compos Struct 2019;212:398-411.

[30] Speck, K., Rittner, S., Bracklow, F., Ewertowski, M., Curbach, M., Cherif, C., "Loop-shaped elements for anchoring carbon reinforcement in concrete", Civil Engineering Design, 2020; 2(4)104-113.

[31] AC434. Acceptance criteria for masonry and concrete strengthening using fabric reinforced cementitious matrix (FRCM) and steel reinforced grout (SRG) composite systems. International Code Council, 2016.

[32] Aveston J, Kelly A. Theory of multiple fracture of fibrous composites. J Mater Sci 1973;8(3):352-362.

[33] GB/T50081-2016. Standard for Test Method of Mechanical Properties on Ordinary Concrete. China Ministry of Construction, Beijing, China, 2016.

[34] BS EN 1015-11, Methods of test for mortar for masonry. Determination of flexural and compressive strength of hardened mortar. British Standard Institution, 2019.

[35] JSCE. Recommendations for design and construction of high performance fiber reinforced cement composites with multiple fine cracks (HPFRCC). Tokyo, 2008.

[36] ACI 549R-13. Guide to design and construction of externally bonded Fabric-Reinforced Cementitious Matrix (FRCM) systems for repair and strengthening concrete and masonry Structures. (2013). American Concrete Institute.

[37] Su MN, Wei LL, Zeng ZW, Ueda T, Xing F, Zhu JH. A solution for sea-sand reinforced concrete beams. Constr Build Mater, (2019); 204:586-596.

[38] Hartig J, Jesse F, Schicktanz K, Häußler-Combe U. Influence of experimental setups on the apparent uniaxial tensile load-bearing capacity of textile reinforced concrete specimens. Mater Struc 2012;45(3):433-46.

[39] Li VC, Wang S, Wu C. Tensile strain-hardening behavior of polyvinyl alcohol engineered cementitious composite (PVA-ECC). ACI MATER J 2001;98(6):483-492.

[40] Li VC. On engineered cementitious composites (ECC). J Adv Concr Technol 2003;1(3):215-230.

[41] D'Antino T, Carozzi FG, Colombi P, Poggi C. Out-of-plane maximum resisting bending moment of masonry walls strengthened with FRCM composites. Compos struct 2018;202:881-96.

[42] D'Antino T, Colombi P, Carloni C, Sneed LH. Estimation of a matrix-fiber interface cohesive material law in frem-concrete joints. Compos Struct 2018;193:103-12..

[43] Cuypers H., Wastiels J, Hegger J, Brameshuber W, Will N. A stochastic cracking theory for the introduction of matrix multiple cracking in textile reinforced concrete under tensile loading. In Proceedings of the 1st International RILEM Symposium. RILEM Technical Committee 2006:193-202.

[44] Carozzi FG, Poggi C. Mechanical properties and debonding strength of Fabric Reinforced Cementitious Matrix (FRCM) systems for masonry strengthening. Compos Part B - Eng 2015;70(1):215-30.

[45] Widom, B. Random sequential addition of hard spheres to a volume. J Chem Phys 1966;44(10): 
3888-94. https://doi.org/10.1063/1.1726548.

[46] Mercedes L, Gil L, Bernat-Maso E. Mechanical performance of vegetal fabric reinforced cementitious matrix (FRCM) composites. Constr Build Mater 2018;175:161-173.

[47] Ascione L, Felice GD, Santis SD., "A qualification method for externally bonded Fibre Reinforced Cementitious Matrix (FRCM) strengthening systems." Compos Part B. 2015, 78:497-506.

[48] Santis S, Felice G., "Tensile behaviour of mortar-based composites for externally bonded reinforcement systems". Compos Part B-Eng. 2015, 68: 401-413.

[49] Minafò G, La Mendola L., "Experimental investigation on the effect of mortar grade on the compressive behaviour of FRCM confined masonry columns." Compos Part B-Eng. 2018, 146: $1-12$.

[50] Ebead U, Younis A. (2019). "Pull-off characterization of FRCM/Concrete interface.” Compos Part B-Eng. 165: 545-553.

(1)

西


543

544

545

546

547

548

549

550

Table 1 Material properties of the carbon fiber meshes

\begin{tabular}{lcccc}
\hline $\begin{array}{l}\text { Type of fiber } \\
\text { meshes }\end{array}$ & $\begin{array}{c}\text { Tensile } \\
\text { strength } \\
(\mathrm{MPa})\end{array}$ & $\begin{array}{c}\text { Elastic } \\
\text { modulus } \\
(\mathrm{GPa})\end{array}$ & $\begin{array}{c}\text { Break } \\
\text { elongation }\end{array}$ & $\begin{array}{c}\text { Fiber area }\left(\mathrm{A}_{\mathrm{f}}\right) \\
\left(\mathrm{mm}^{2} / \mathrm{mm}\right)\end{array}$ \\
\hline $\mathrm{T} 1$ & 2077 & 196 & 0.011 & 0.0462 \\
$\mathrm{~T} 2$ & 441 & 66 & 0.007 & 0.1170 \\
$\mathrm{~T} 3$ & 2225 & 195 & 0.012 & 0.0462 \\
\hline
\end{tabular}

Table 2 Mixing proportion and material properties of the cementitious matrix

Components $\quad$ M1 (\%) M2 (\%) M3 (\%) M4 (\%) M5 (\%) M6 (\%) M7 (\%)

\begin{tabular}{|c|c|c|c|c|c|c|c|}
\hline Cement & 100 & 100 & 100 & 100 & 100 & 100.00 & \\
\hline Limestone powder & l & / & l & l & / & 14.29 & \\
\hline Silica fume & l & l & I & I & I & 21.43 & \\
\hline Ground granulated blast furnace slag & l & l & / & / & l & 107.14 & $\frac{0}{3}$ \\
\hline Silica sand & 100 & 100 & 100 & 100 & 100 & 71.43 & $\frac{\pi}{\pi}$ \\
\hline Water & 35 & 35 & 35 & 35 & 35 & 46.14 & $\stackrel{\overparen{I}}{\Xi}$ \\
\hline PE fiber & l & l & I & l & / & 2.86 & \\
\hline Carbon fiber & 0 & 0.5 & 0.75 & 1 & 1.25 & l & \\
\hline Polycarboxylate-based high range water & 0.18 & 0.18 & 0.18 & 0.18 & 0.18 & 9.71 & \\
\hline $\begin{array}{l}\text { Water } /(\text { Cement }+ \text { Silica fume }+ \\
\text { Ground granulated blast furnace) }\end{array}$ & 0.35 & 0.35 & 0.35 & 0.35 & 0.35 & 0.22 & 0.35 \\
\hline Compressive strength (MPa) & 60.1 & 53.2 & 51.7 & 52.4 & 52.0 & 79.4 & 34.3 \\
\hline Tensile strength (MPa) & 3.3 & 3.9 & 4.3 & 4.0 & 4.1 & 3.7 & 4.7 \\
\hline Elastic modulus (GPa) & 12.4 & 35.2 & 30.6 & 43.2 & 27.1 & 36.7 & 20.1 \\
\hline
\end{tabular}


Table 3 Labeling scheme used for the test specimens

\begin{tabular}{cccc}
\hline Specimens & $\begin{array}{c}\text { Type of } \\
\text { cementitious } \\
\text { matrix }\end{array}$ & $\begin{array}{c}\text { Type of fiber } \\
\text { mesh }\end{array}$ & $\begin{array}{c}\text { Node } \\
\text { treatment }\end{array}$ \\
\hline M1-T1 & M1 & T1 & No \\
M2-T1 & M2 & T1 & No \\
M3-T1 & M3 & T1 & No \\
M4-T1 & M4 & T1 & No \\
M5-T1 & M5 & T1 & No \\
M6-T1 & M6 & T1 & No \\
M7-T2 & M7 & T2 & No \\
M1-T3 & M1 & T3 & Yes \\
\hline
\end{tabular}

555

556

557

558

559

560

Table 4 Average test results for FRCM

\begin{tabular}{ccccccc}
\hline Specimens & $\begin{array}{c}\text { Carbon fiber } \\
\text { content* }(\%)\end{array}$ & $\begin{array}{c}f_{t} \\
(\mathrm{MPa})\end{array}$ & $\begin{array}{c}f_{u} \\
(\mathrm{MPa})\end{array}$ & $\begin{array}{c}\varepsilon_{u} \\
(\%)\end{array}$ & $\begin{array}{c}E_{1} \\
(\mathrm{GPa})\end{array}$ & $\begin{array}{c}E_{2} \\
(\mathrm{GPa})\end{array}$ \\
\hline M1-T1 & 0.00 & 682 & 1225 & 0.81 & 2904 & 74 \\
M2-T1 & 0.50 & 916 & 1257 & 0.82 & 7634 & 50 \\
M3-T1 & 0.75 & 991 & 1307 & 0.75 & 6638 & 80 \\
M4-T1 & 1.00 & 876 & 1276 & 0.90 & 9367 & 57 \\
M5-T1 & 1.25 & 898 & 1251 & 0.70 & 3650 & 75 \\
M1-T3 & 0.00 & 725 & 1740 & 1.27 & 3201 & 126 \\
M6-T1 & 0.00 & 640 & 2168 & 0.96 & 5970 & 136 \\
M7-T2 & 0.00 & 210 & 196 & 0.52 & 1110 & 30 \\
\hline
\end{tabular}

561

* Percentage to cement weight 
Table 5 Collected tensile test results for FRCM composites

\begin{tabular}{|c|c|c|c|c|c|c|c|c|c|}
\hline References & $\begin{array}{c}\text { Type pf fiber } \\
\text { mesh }\end{array}$ & $\begin{array}{c}\text { Type of } \\
\text { grips }\end{array}$ & $\begin{array}{c}f_{t} \\
(\mathrm{MPa})\end{array}$ & $\begin{array}{c}f_{u} \\
(\mathrm{MPa})\end{array}$ & $\begin{array}{c}f_{f} \\
(\mathrm{MPa})\end{array}$ & $\begin{array}{c}\varepsilon_{u} \\
(\%)\end{array}$ & $\begin{array}{c}\varepsilon_{f} \\
(\%)\end{array}$ & $\begin{array}{c}E_{l} \\
(\mathrm{GPa})\end{array}$ & $\begin{array}{c}E_{2} \\
(\mathrm{GPa}) \\
\end{array}$ \\
\hline Larrinaga et al. [21] & basalt & clamping & 338 & 1088 & 1160 & 2.15 & 1.73 & 1446 & 43 \\
\hline Bertolesi et al. [7] & $\mathrm{PBO}$ & clamping & 495 & 3316 & 3905 & 1.69 & 1.69 & 878 & 157 \\
\hline \multirow{2}{*}{ Arboleda et al. [19] } & carbon & clamping & 482 & 1492 & 1900 & 0.74 & 0.94 & 798 & 186 \\
\hline & PBO & clamping & 890 & 3316 & 3900 & 1.69 & 1.80 & 1877 & 216 \\
\hline \multirow{3}{*}{ Ascione et al. [47] } & carbon & clamping & 137 & 1222 & 1914 & 0.83 & 1.18 & 164 & 131 \\
\hline & glass-aramid & clamping & 511 & 1784 & 1829 & 2.02 & 2.15 & 274 & 96 \\
\hline & $\begin{array}{c}\text { basalt-stainless } \\
\text { steel }\end{array}$ & clamping & 124 & 345 & 1471 & 0.54 & 3.00 & 101 & 61 \\
\hline \multirow{3}{*}{ Carozzi \& Poggi [44] } & PBO & clamping & 724 & 3319 & 3900 & 1.69 & 1.81 & 1298 & 216 \\
\hline & glass & clamping & 307 & 872 & 1233 & 0.69 & 2.22 & 699 & 64 \\
\hline & carbon & clamping & 438 & 1492 & 1944 & 0.74 & 0.94 & 943 & 186 \\
\hline Santis \& Felice [48] & glass-aramid & clamping & 404 & 1851 & 1829 & 2.20 & 1.80 & 911 & 91 \\
\hline Caggegi et al. [22] & basalt & clamping & 592 & 912 & 1089 & 0.75 & 1.94 & 1053 & 53 \\
\hline \multirow{3}{*}{$\begin{array}{l}\text { D'Antino \& Papanicolaou } \\
\text { [20] }\end{array}$} & carbon & clamping & 229 & 838 & 938 & 0.73 & 1.80 & 1432 & 114 \\
\hline & carbon & clamping & 1645 & 2745 & 1890 & 0.86 & 0.94 & 3351 & 188 \\
\hline & glass & clamping & 722 & 1221 & 660 & 1.38 & 1.41 & 1288 & 53 \\
\hline Minafò and Mendola [49] & glass & clamping & 606 & 1317 & 1400 & 4.00 & 4.38 & 47 & 32 \\
\hline \multirow{2}{*}{ Arboleda et al. [19] } & carbon & clevis & 458 & 1031 & 1900 & 1.00 & 0.94 & 349 & 80 \\
\hline & PBO & clevis & 375 & 1664 & 3900 & 1.76 & 1.80 & 1877 & 128 \\
\hline Santis \& Felice [48] & glass-aramid & clevis & 404 & 1238 & 1829 & 1.40 & 1.80 & 911 & 53 \\
\hline \multirow{4}{*}{ Donnini et al. [15] } & carbon fiber & clevis & 986 & 575 & 4900 & 0.01 & 2.00 & 67669 & 1 \\
\hline & carbon fiber & clevis & 1088 & 713 & 4900 & 0.01 & 2.00 & 67669 & 30 \\
\hline & carbon & clevis & 875 & 1358 & 4900 & 0.02 & 2.00 & 67669 & 42 \\
\hline & carbon & clevis & 782 & 1366 & 4900 & 0.03 & 2.00 & 67669 & 49 \\
\hline \multirow{3}{*}{$\begin{array}{l}\text { D'Antino \& Papanicolaou } \\
\text { [20] }\end{array}$} & carbon & clevis & 333 & 417 & 938 & 0.79 & 1.80 & 693 & 417 \\
\hline & carbon & clevis & 433 & 1393 & 1890 & 0.86 & 1.18 & 1131 & 172 \\
\hline & glass & clevis & 281 & 593 & 660 & 1.97 & 1.41 & 630 & 39 \\
\hline Donnini et al. [29] & glass & clevis & 604 & 1275 & 1405 & 4.90 & 2.40 & 1709 & 29 \\
\hline \multirow{2}{*}{ Ebead \& Younis [50] } & carbon & clevis & 260 & 970 & 3580 & 1.25 & 1.50 & 378 & 75 \\
\hline & $\mathrm{PBO}$ & clevis & 487 & 1235 & 4980 & 0.90 & 1.80 & 601 & 112 \\
\hline
\end{tabular}

